\title{
WAVE AND CURRENT GENERATION IN WAVE FLUMES USING AXIAL-FLOW PUMPS
}

\author{
Aurélien Babarit, Simon Delvoye, Vincent Arnal, Laurent Davoust, Jeroen Wackers, Félicien Bonnefoy \\ Ecole Centrale de Nantes - CNRS \\ Nantes, France
}

\begin{abstract}
We investigate a new concept for wave and current generation. It consists of axial-flow pumps driven such as to generate an oscillatory flow through an orifice located at one end of the flume. Oscillations of the flow lead to the generation of water waves at the free surface. If the average of the flow is different from zero, a current is generated that superposes on the waves. In this study, we explored the technical capabilities of this concept and the influence of geometric parameters on wave and current generation. We used numerical and experimental modelling. Most noticeably, the numerical results indicate that this concept is well suited for the generation of long and high waves. An experimental setup has been designed and built. We used it to make an experimental proof of concept for the wave and current generation, including waves propagating against the current.
\end{abstract}

\section{INTRODUCTION}

The usual approch to generate waves in wave tanks is to use rigid bodies with oscillating motions. Current is usually generated using pumps and a circulating duct under the bottom of the tank or a circulating channel on the side of the tank. Wave and current generation is usually obtained by combining the two systems. This architecture can be found in wave tanks at SINTEF Ocean in Norway, at MARIN in The Netherlands, in France at Ifremer Boulogne or Océanide.

From the physics' point of view, wave generation is the result of the application of an oscillating normal velocity boundary condition on the wall of the tank [1]. Wave propagation being a deterministic process, any system that can generate the same boundary condition as a conventional wavemaker (say a bottom hinged flap or piston-type wavemaker) shall achieve the same wave generation in the tank.

Elaborating on this idea, Ecole Centrale de Nantes has proposed a new wavemaking system using axial-flow pumps instead of rigid bodies [2], see Fig. 1. The axial-flow pumps are located in ducts that connect the wave flume to a back reservoir. The pumps are controlled in order to generate an oscillating flow. At the outlet of the duct on the wave flume's side, the flow velocities are similar to the ones obtained with conventional wavemakers. Therefore, waves are generated in the wave flume.

A first unique feature of this system is that it can generate both waves and current. Indeed, current can easily be obtained by adjusting the control of the axial-flow pumps such as the average flow through the ducts is non-zero. In this case, obviously, it is mandatory for current generation to include a circulating duct or a circulating channel connecting the end of the wave flume back to the back reservoir. Depending on the orientation of the average flow, one can generate conditions with waves propagating with or propagating against the current.

A second interesting feature of the proposed system is that it makes it easier to generate large amplitudes waves than with conventional wavemakers. Indeed, the wave amplitude is limited by the maximum available stroke for conventional wavemakers. As an example, Fig. 2 shows a comparison of measurements of the maximum wave height in the large wave tank of Ecole Centrale de Nantes and the maximum wave height that can be obtained when the wavemakers are used with maximum stroke $(1.76 \mathrm{~m})$. The finite stroke limit was obtained using the linear wavemaker theory [1]. For wave periods above $4 \mathrm{~s}$, one can see 


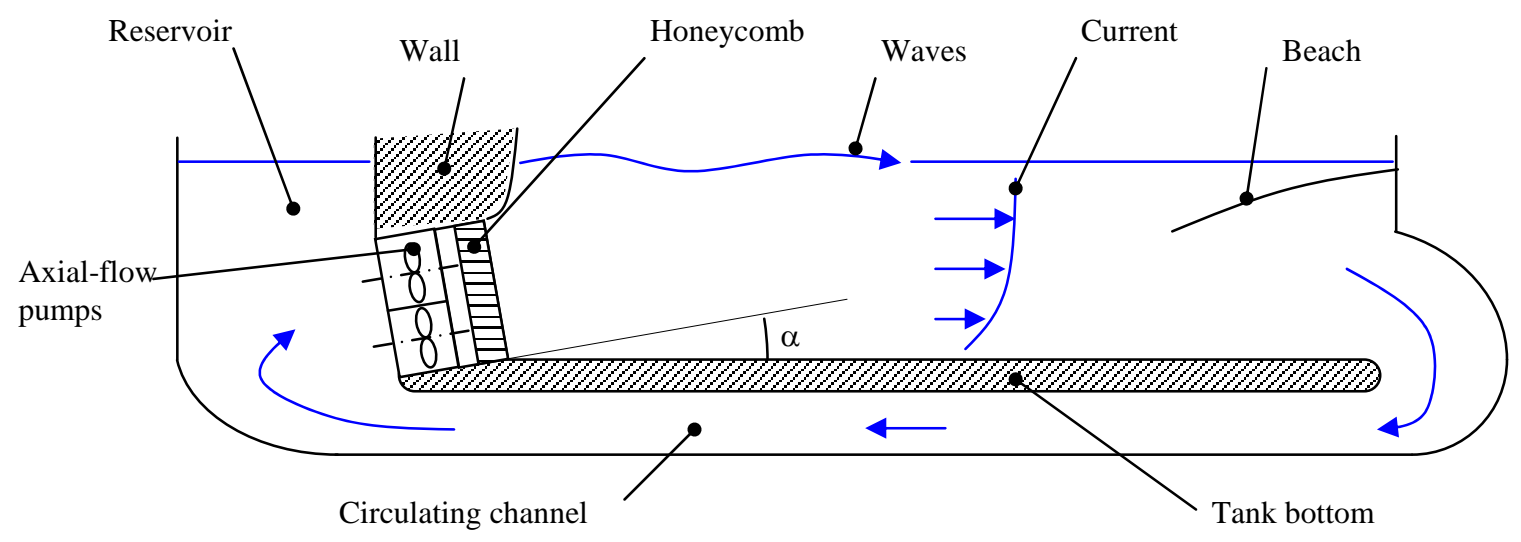

FIGURE 1. SKETCH OF THE PROPOSED WAVE AND CURRENT GENERATION SYSTEM.

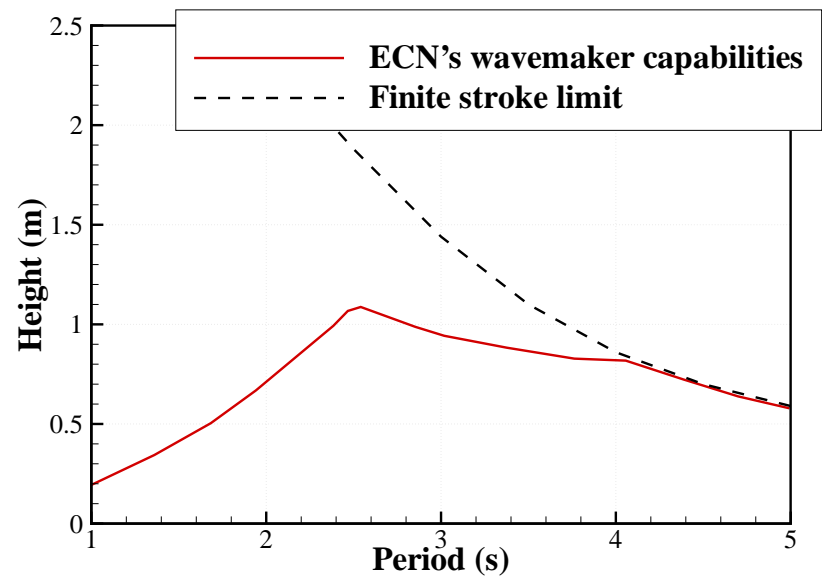

FIGURE 2. COMPARISON OF MEASUREMENTS OF THE MAXIMUM WAVE HEIGHT IN THE LARGE WAVE TANK OF ECOLE CENTRALE DE NANTES AND CALCULATIONS USING THE LINEAR WAVEMAKER THEORY OF THE WAVE HEIGHT FOR A STROKE OF $1.76 \mathrm{~m}$. FOR WAVE PERIODS BELOW $2.5 \mathrm{~s}$, THE WAVE HEIGHT IS LIMITED BY WAVE BREAKING. BETWEEN 2.5 AND $4.5 \mathrm{~s}$, IT IS LIMITED BY THE MAXIMUM POWER OF THE ELECTRIC MOTORS. ABOVE $4 \mathrm{~s}$, THE WAVE HEIGHT IS LIMITED BY THE MAXIMUM STROKE OF THE WAVEMAKERS.

that the height of the generated waves is limited by the finite stroke. This limitation does not apply to the proposed system.

Therefore, it appears that the proposed system may be a relevant alternative to conventional technologies for wave and current generation in the context of ocean engineering. Exploratory studies have been conducted at Ecole Centrale de nantes in order to further investigate its potential. It includes a parametric study using numerical modelling in order to assess the effect of geometric and dynamic parameters on the generated wave characteristics. Using the results of the parametric study, an experimental set-up was designed and built . It allowed an experimental proof-of-concept that included generation of waves propagating against the current. The aim of the present paper is to present those works.

\section{PARAMETRIC STUDY List of identified relevant parameters}

For the new system, there are many geometric parameters that can have a significant effect on the characteristics of the generated wave and current:

- Submergence depth of the duct outlet (distance $d$ in Fig. 3). In deep water conditions, it is expected that the duct outlet should be close to the free surface for high energy efficiency. However, the minimum distance to the free surface may be limited by the amplitude of the maximum wave troughs to avoid ventilation at the axial-flow pumps, which could be damaging. Therefore, the submergence depth of the duct outlet is expected to be a trade-off between energy efficiency and the maximum design wave amplitude.

- Ratio of the duct outlet's height to the water depth and angle of the duct axis with respect to the bottom of the flume. For current generation, the most homogeneous horizontal velocity profile across the water column is expected to be obtained with the height of the duct outlet (distance $H$ in Fig. 3) equal to the depth of the flume (denoted $D$ in Fig. 3). However, this configuration is not possible in practice because it could lead to ventilation issues for the pumps in the wave troughs. Therefore, the top of the outlet duct should be sufficiently submerged. To avoid a deficit in the current velocity profile close to the free surface, the duct axis should be slightly inclined (angle $\alpha$ in Fig. 1). 


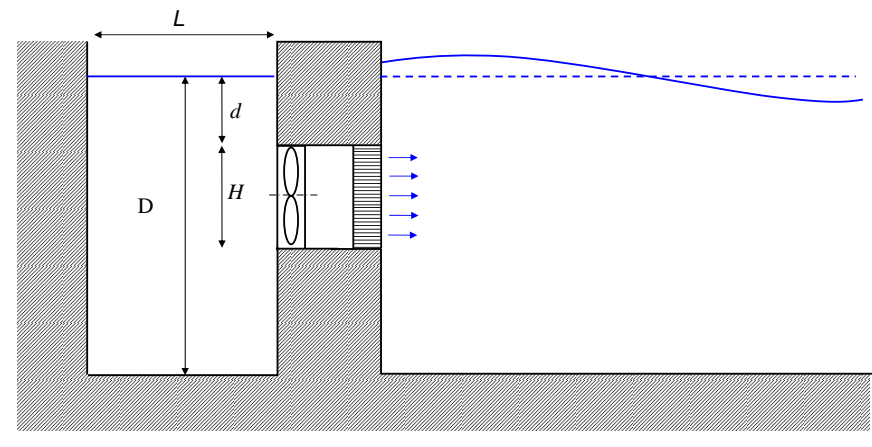

FIGURE 3. DEFINITIONS OF TOP OUTLET DUCT SUBUMERGENCE DEPTH $d$, OUTLET DUCT HEIGHT $H$ AND DUCT LENGTH $L$.

- Geometries of the duct inlet and outlet, duct and honeycomb length (see Fig. 1). A honeycomb is required at the duct outlet in order to filter out large eddies that could be generated by the pumps and reduce the turbulence level in the flume. The geometries of the duct inlet and outlet, of the duct and of the honeycomb govern the head losses through the system. They may have a significant effect on the energy efficiency of the system. Also, the geometry of the duct outlet may have an influence on the generation of parasitic waves (free or bound harmonic waves).

- Length of the back reservoir (denoted $L$ in Fig. 3)). Depending on its length, sloshing may occur in the back reservoir. It could make the duct inlet flow conditions (pressure, velocities) vary with time which could be an issue for the pumps (particularly with respect to control). Sloshing issues may be reduced by adding a wave damping system in the back reservoir. It may be a damping beach, wave-screens or even floats or floating mats on the free surface.

- Geometry of the inlet of the circulating duct at the end of the wave flume (see Fig. 1). It is expected that it is critical for the quality of the current in case of generation of conditions with waves propagating against the current. Also, it creates a head loss thus it has an effect on the energy efficiency of the system.

Obviously, the waves and current in the wave flume also depend on the dynamic characteristics of the volume flow rate at the duct outlet. They are:

- Average volume flow rate. The average volume flow rate through the pumps sets the current including the direction of the current.

- Spatial homogeneity of the horizontal velocity. The best configuration is when the velocity profile at the duct outlet corresponds to the target flow (which can be waves only, waves and current, current only). If there are large variations of the flow velocity in the vertical directions (waves in deep water condition, sheared current), it may be relevant to use columns of independently controlled pumps (several pumps located on top of each other).

- Harmonic content (amplitudes and phases of the harmonics). The harmonic content of the volume flow rate at the duct outlet should be controlled according to the wave conditions (regular or irregular waves, deep water or finite water depth conditions). Like for wave generation with conventional wavemakers, it may be necessary to include corrective terms in the control of the axial-flow pumps to reduce the rate of parasitic waves [3].

\section{Effect of submergence depth and heigth of duct outlet}

Here, the technical characteristics of the large wave tank of Ecole Centrale de Nantes are used as references. Its water depth is $5 \mathrm{~m}$. The wavemakers are oscillating flaps. Their height is $2.85 \mathrm{~m}$. Thus, we chose to study the effect of the submergence depth of the top of the outlet duct (heigth $d \mathrm{~d}$ in Fig. 3) while maintaining the total height of the submergence depth and duct outlet equal to the height of the flaps of Ecole Centrale de Nantes' wave tank (i.e $d+H=2.85 \mathrm{~m}$ ).

The well-known wavemaker theory is used [1]. We assume that the wave making system generates a perfect uniform horizontal velocity through the duct outlet. The MATLAB routines developed by Meylan [4] were used to calculate the amplitude of the propagating mode and the amplitudes of the evanescent modes. We varied the duct outlet top submergence depth and the wave period. Results for the ratio of the propagating mode's wave height (two times the amplitude) to the amplitude of the volume flow rate through the duct outlet are shown in Fig. 4 as well as results for the ratio of the wave heigth to the horizontal flow velocity amplitude.

As expected, one can see that, for a given wave period, the wave heigth decreases with increasing submergence depth. Assuming that a key technical constraint of the axial-flow pumps is the maximum volume flow rate that they can deliver, it shows that the top of the duct outlet should be as close as possible to the free surface for high wave generation.

Less intuitively, one can see that the ratio of wave height to volume flow rate or horizontal velocity increases with increasing wave period. In other words, the longer the wave period is, the greater the wave heigth will be. This is a clear advantage of the proposed new wave making system versus conventional wavemakers, for which the maximum wave height decreases with increasing wave period because of stroke limitation (see Fig. 2). It shows that the proposed new system is well suited for large and long waves generation. For example, with a duct outlet of 1.85 $\mathrm{m}$ and a top submergence depth of $1 \mathrm{~m}$, a system that could deliver a maximum volume flow rate of $1 \mathrm{~m}^{3} \cdot \mathrm{s}^{-1}$ would generate 

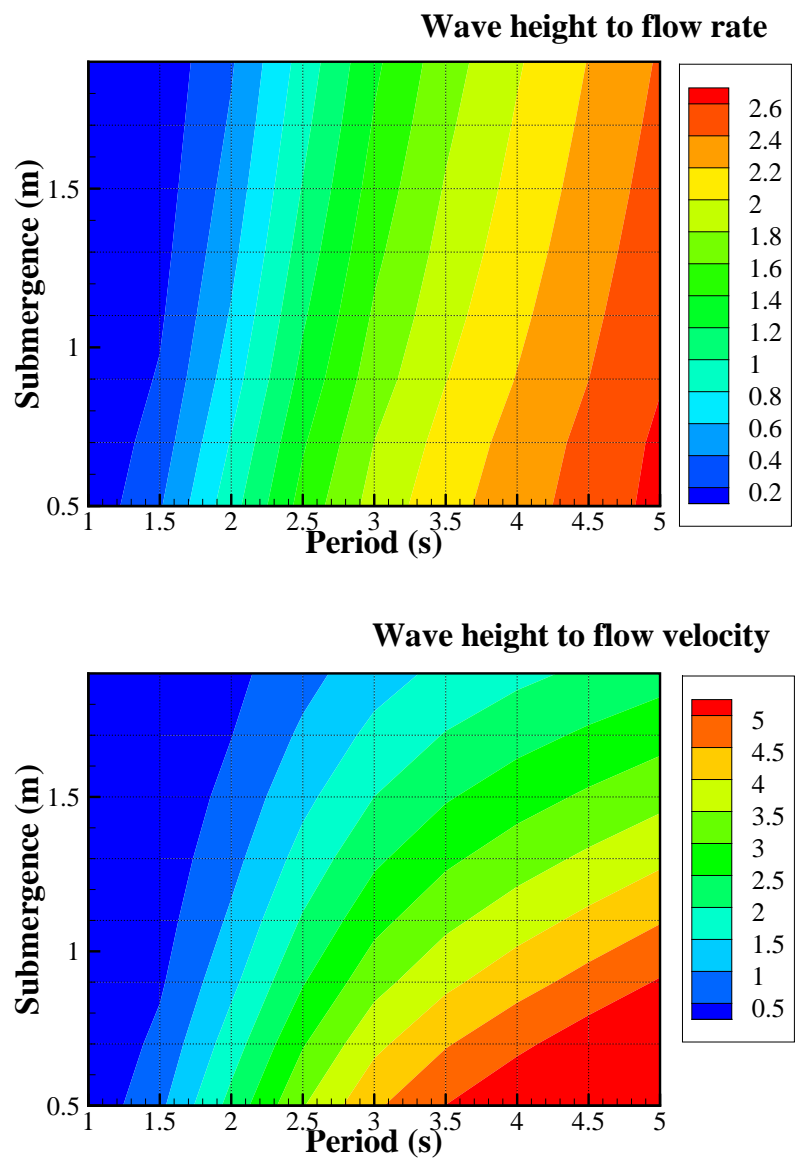

FIGURE 4. RATIO OF PROPAGATING MODE'S WAVE HEIGHT TO VOLUME FLOW RATE AMPLITUDE (TOP, IN $\mathrm{m} /\left(\mathrm{m}^{2} \cdot \mathrm{s}^{-1}\right)$ ) AND TO FLOW VELOCITY AMPLITUDE (BOTTOM, IN $\mathrm{m} /\left(\mathrm{m} . \mathrm{s}^{-1}\right)$ ) AS FUNCTIONS OF WAVE PERIOD AND TOP SUBMERGENCE OF DUCT OUTLET .

a wave of $2 \mathrm{~m}$ height for a period of $4 \mathrm{~s}$. For this configuration, a flow rate of $1 \mathrm{~m}^{3} . \mathrm{s}^{-1}$ corresponds to a maximum horizontal flow velocity through the duct outlet of $0.54 \mathrm{~m} . \mathrm{s}^{-1}$. This level of flow velocity appears rather moderate, thus we believe that it is achievable in practice. For sake of comparison, it would require a stroke of approximately $4 \mathrm{~m}$ for the flap-type wavemaker of ECN's large wave tank to generate waves of the same height and period.

\section{Optimization of duct geometry}

The wavemaker theory is not relevant to study the effect of the details of the duct geometry on wave and current generation, mainly because of the assumption of irrotational flow. Therefore, we developed a bidimensional numerical model using the
Navier-Stokes solver ISIS-CFD [5] (which is a component of the numerical framework FINE/Marine). Now, the length of the wave flume is $30 \mathrm{~m}$ and the water depth is $1 \mathrm{~m}$. The recirculation duct is located beneath the flume bottom. This numerical model allows the effect of details of the duct geometry to be studied including the effect of the angle $\alpha$ (see Fig. 1) and the effect of the shape of the duct outlet.

Figure 5 shows an example of wave generation simulated with the numerical model. We consider that the pumping systems consist of two $40 \mathrm{~cm}$ diameter axial-flow pumps one on top of the other. The effect of the axial-flow pumps is taken into account by prescribing the flow velocity at the location of the pumps (black line across the flow in the middle of the duct in Fig. 5). The pumps are separated by a wall parallel to their axis. The total height of the duct is $H=80 \mathrm{~cm}$ (see Fig. 3). Let us recall that the water depth is $D=1 \mathrm{~m}$, thus the water clearance above the top of the duct's outlet is $20 \mathrm{~cm}$.

The exact geometry of the axial-flow pumps and of the honeycomb hasn't been modelled. Note that they could have been with ISIS-CFD. However the numerical complexity (mesh complexity and CPU time) would have been disproportionate to the objectives of this concept study. Instead, we used a simplified approach. A homogeneous flow velocity field has been prescribed at the location of the pumps (black lines across the flow in the middle of the duct in Fig. 5). This approach assumes that the physical effect of the honeycomb is perfect in terms of filtering the eddy structures and smoothing the spatial variation of the flow velocity. It does not take into account the injection of residual turbulence in the flow.

The SST k- $\omega$ turbulence model was used. Starting from zero velocity, a ramp was found to be unnecessary for the introduction of the pump velocity in case of wave generation only. However, a ramp was found to be critical in cases of current generation to avoid exciting the sloshing modes of the flume. A ramp duration of $40 \mathrm{~s}$ was used. Mesh convergence was obtained for meshes with number of cells of order of $10^{5}$. The computational time was of order of $1 \mathrm{~h}$ per wave period on a 5 years-old desktop computer.

Figure 5 shows a snapshot of the wavefield in the wave flume and in the back reservoir after approximately $10 \mathrm{~s}$ of simulation time. The wave period is $2 \mathrm{~s}$ in this simulation. On the right, one can see that waves have been generated and propagated from the wavemaker. Close to the wavemaker, one can see that the system also generates higher harmonic waves despite the regular forcing (the prescribed flow velocity at the pumps varies sinusoidally with time with a $2 \mathrm{~s}$ period). Like for wave generation with conventional wavemakers, it may be necessary to include corrective terms in the control of the axial-flow pumps to reduce the rate of these parasitic waves. Building on the work of [3], we implemented corrections in the prescribed flow velocity, but it didn't improve the results so far. Further research appears to be necessary. 


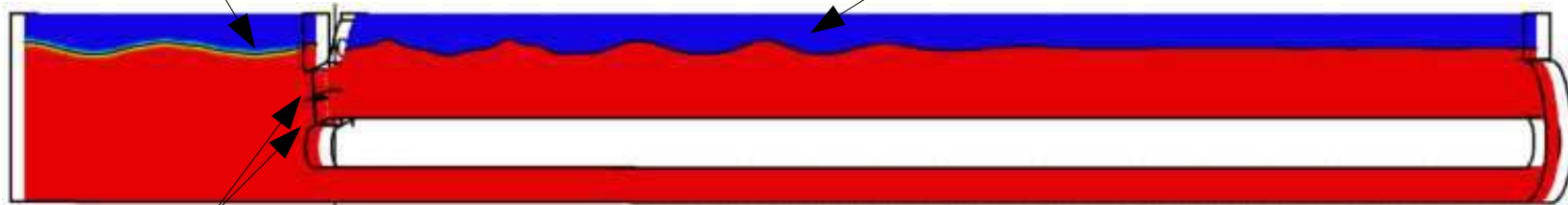

Prescribed flow velocity

FIGURE 5. EXAMPLE OF WAVE GENERATION SIMULATED USING THE ISIS-CFD BASED NUMERICAL WAVE FLUME. THE EFFECT OF THE AXIAL-FLOW PUMPS IS MODELLED BY PRESCRIBING THE FLOW VELOCITY AT THE LOCATION OF THE PUMPS (BLACKS LINE ACROSS THE FLOW IN THE MIDDLE OF THE DUCT). THE WAVE PERIOD IS $2 \mathrm{~s}$.

On the left in Fig. 5, one can see that waves are also generated in the back reservoir. They may have an effect on the overall dynamic response of the system. To mitigate this effect, it may be necessary to include wave damping systems in the back reservoir. This has not been investigated yet.

Optimization of angle $\alpha$. The angle $\alpha$ is a key parameter regarding the homogeneity of the horizontal flow velocity in case of current generation. Angles of $5^{\circ}, 10^{\circ}, 15^{\circ}, 20^{\circ}$ and $30^{\mathrm{O}}$ were tested numerically. The horizontal velocity profile at a distance of $12 \mathrm{~m}$ from the wavemaker for each configuration is shown in Fig. 6.

As expected, there is a significant deficit in the horizontal velocity close to the flume bottom which can be explained by the development of the bottom boundary layer. One can see that its thickness is approximately $20 \mathrm{~cm}$ at $12 \mathrm{~m}$ of the wavemaker. It appears that there is also a deficit in the horizontal velocity close to the free surface. It may also be explained by friction of the upper water layer with the air on top of the flume.

Overall, one can see that the velocity profile is the flatest for inclination angles of $5^{\mathrm{O}}$ and $10^{\mathrm{O}}$. For $10^{\mathrm{O}}$. However, one may notice a small deficit in the velocity in the middle of the water column for the $10^{\circ}$ configuration, which is the signature of the separating wall between the two axial-flow pumps in the numerical model (see Fig. 5).

Optimization of duct's outlet shape. It may be expected that the shape of the duct's outlet has an effect on the quality of the generated waves. To measure the quality of the waves, we have chosen the rate of generated harmonics (ratio of the amplitude of parasitic waves with respect to the amplitude of the targed wave). Several shapes have been tested among which two examples are shown in Fig. 7. The amplitude of the parisitic waves have been measured using an array of numerical wave gauges Surprisingly, results indicate that, for all the con-

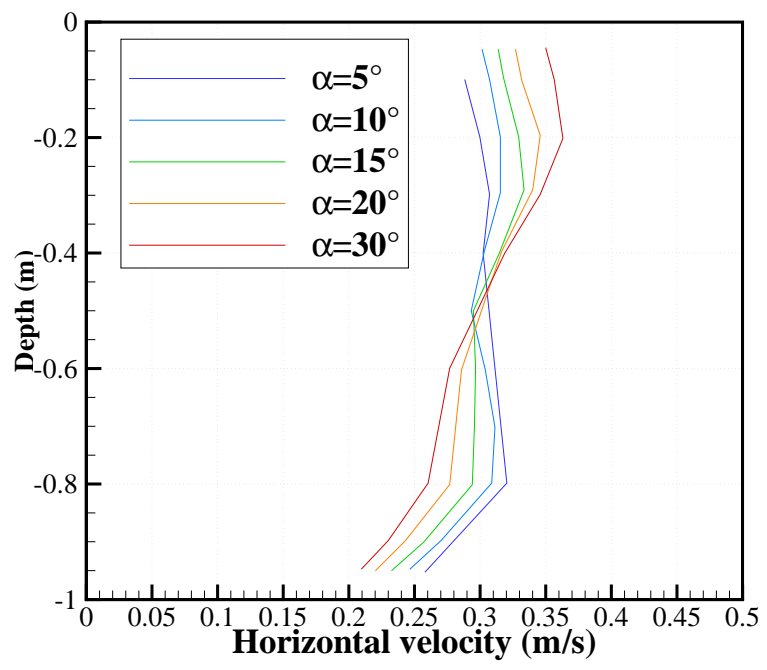

FIGURE 6. COMPARISON OF VERTICAL PROFILE OF THE HORIZONTAL FLOW VELOCITY FOR SEVERAL ANGLES $\alpha$ OF INCLINATION OF THE WAVE AND CURRENT GNERATION SYSTEM.

figurations that have been tested, the effect of the shape of the duct's outlet on the quality of the generated waves is negligible.

\section{EXPERIMENTAL VALIDATION}

To further qualify the new wave and current generation system, a new wave flume has been designed and built at Ecole Centrale de Nantes. It is immersed in the circulation channel of Ecole Centrale de Nantes. The numerical findings were used for the design of the experimental set-up. A 1/3 scale was chosen with respect to the dimensions of the numerical wave flume. The length 

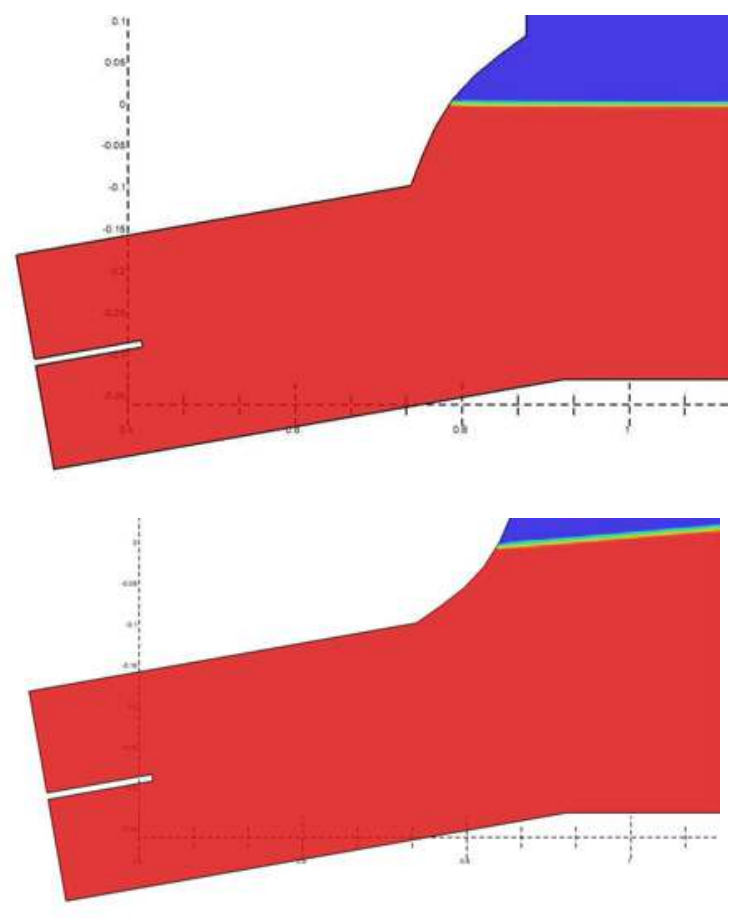

FIGURE 7. EXAMPLES OF SHAPES THAT HAVE BEEN TESTED FOR THE DUCT'S OUTLET.

of the flume is $12 \mathrm{~m}$, the water depth is $0.36 \mathrm{~m}$. The width of the flume is $0.144 \mathrm{~m}$. A damping beach is included at one end of the flume. Figure 8 shows a sketch and pictures of the experimental set-up.

The wave flume was built with ARCANE modular aluminum rails. The walls are made with Komacell PVC sheets (10 $\mathrm{mm}$ thickness). The wave and current generation system consists in a structure on which are mounted the equipments. The structure allows the inclination angle $\alpha$ between the axis of the duct and the bottom of the flume to be varied. The wave and current generation system includes two $1.5 \mathrm{~kW}$ DC electric motors (Parvex 5S540C) mounted on the top of the supporting structure. They drive using a belt the shafts of two propellers that are used as axial-flow pumps. The propellers are Side Power SE30 bow thrusters. The diameter of the propellers is $125 \mathrm{~mm}$. Each is mounted in a cylindrical duct of $126 \mathrm{~mm}$ internal diameter. The cylindrical ducts are connected to a greater duct with rectangular section. Its length and its height are $500 \mathrm{~mm}$. It is expected to allow the flows from the two propellers to be mixed. Then, the flow goes through a honeycomb whose length is $250 \mathrm{~mm}$. Finally, a diffuser allows a smooth transition from ducted flow to free surface flow.
The wave elevation is measured using resistive wave gauges at several locations in the wave flume. The current is measured using a cup-type current meter. The current meter is mounted on a mast that allows the current to be measured at several depths in the water column. Velocitymeters were mounted on the shaft of the electrical motors in order to to control the rotational velocity. Both motors are controlled with the same control law. Feed-in current and voltage to the motors were measured to calculate the overall energy efficiency of the system.

\section{Current generation capability}

Firstly, we investigated the effect of the inclination angle $\alpha$ on the velocity profile at a distance of 5 meters from the wavemaker. The vertical profile of the velocity was measured for $5^{\circ}$, $10^{\circ}, 15^{\circ}$ and $20^{\circ}$. The experimental results confirmed the numerical results: the most homogeneous profiles were obtained with the smallest angles. In the following, $5^{\circ}$ has been retained for the inclination angle. Figure 9 shows the vertical velocity profile for several rated velocities. Tests included the generation of negative current (current coming from the end of the flume to the wavemakers) which was obtained by changing the direction of rotations of the propellers. One can see that the homogeneity of the current is very good for positive currents. For negative currents, it is not as good as for positive currents but we believe that it is still acceptable. The difference in the quality of the vertical velocity profiles between positive and negative currents is attributed to the different end conditions between the two cases.

\section{Wave generation capability}

For wave generation, the rotational velocity of the electric motors is controlled. It follows a harmonic function. The same control is applied to both motors. The period and the amplitude of the rotational velocity are varied in order to quantify the wave generation capabilities of the set-up. The top two graphs in Fig. 10 show the results of an experiment with period $0.8 \mathrm{~s}$ and motors' rotational velocity amplitude $400 \mathrm{rpm}$. The motors are started at $t=0 \mathrm{~s}$. As expected, one can see that waves are generated and that they propagate in the wave flume. In this example, the wave height is approximately $45 \mathrm{~mm}$. Fourier analysis was performed on the wave signal. It showed that the generated waves are not perfect. Parasitic harmonics are also generated by the system.

In the experiments, it was observed that the measured wave height decreases with increasing distance from the wavemaker, see Fig. 11. This phenomenon can be explained by wall friction on the wall of the flume [6]. The decay rate is related to the flume width (the narrower the flume is, the greater the decay rate will be). Using linear curve fitting, the wave height for a wide flume was estimated from the experimental results.

Figure 12 shows the wave height (extrapolated for a wide flume) as a function of the square of the rotational velocity am- 

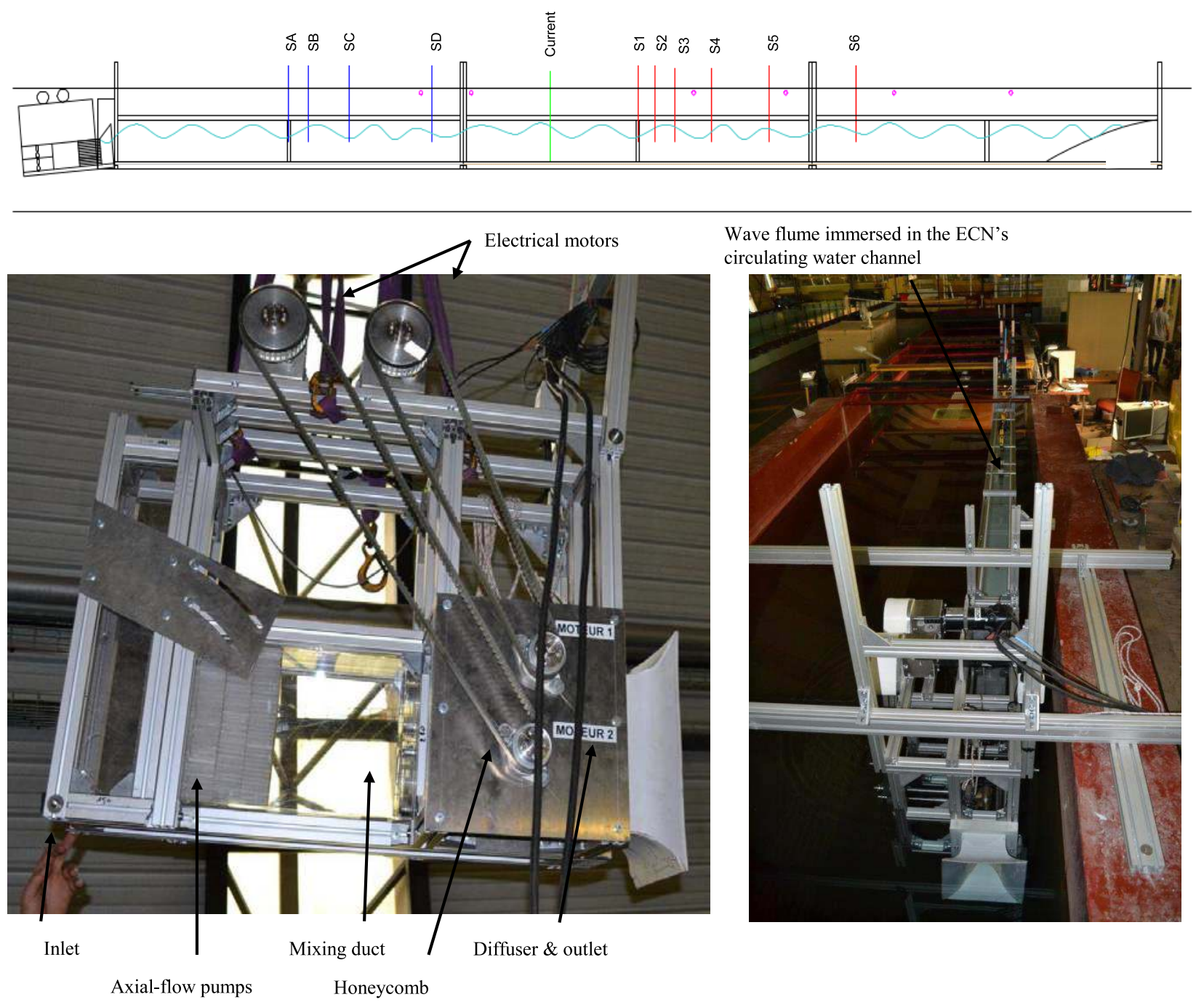

FIGURE 8. SKETCH (ON TOP) AND PICTURES (ON THE LEFT: WAVE AND CURRENT GENERATION SYSTEM, ON THE RIGHT: ASSEMBLED WAVE FLUME IN THE CIRCULATING WATER CHANNEL) OF THE EXPERIMENTAL SETUP THAT WAS INSTALLED AND TESTED IN THE CIRCULATING WATER CHANNEL OF ECOLE CENTRALE DE NANTES. THE SKETCH SHOWS THE LOCATION OF THE WAVE PROBES (RED AND BLUE LINES) AND THE CURRENTMETER (GREEN LINE).

plitude and for several wave periods. One can see that, up to approximately $500 \mathrm{rpm}\left(250000 \mathrm{rpm}^{2}\right)$, the wave height increases linearly with the square of the rotational velocity amplitude. It can be explained by recalling that, for a propeller, the thrust force is related to the square of the rotational velocity. From the fluid perspective, the thrust corresponds to a pressure over a surface perpendicular to the flow. In wave theory, the pressure is directly proportional to the wave height, thus it makes sense that the wave height is linearly related to the square of the rotational velocity amplitude. Above $500 \mathrm{rpm}\left(250000 \mathrm{rpm}^{2}\right)$, one can see the wave height - rotational velocity curves curve until reaching a limit which depends on the wave period. This limit is significantly smaller than the breaking limit. At present, the reasons for this difference are unclear to us.

Figure 12 also shows that the wave height increases with increasing period for a given rotational velocity amplitude. For a rotational velocity of $500 \mathrm{rpm}$, the increase appears to be approximatively linear with the period $(59 \mathrm{~mm}$ wave height for a 


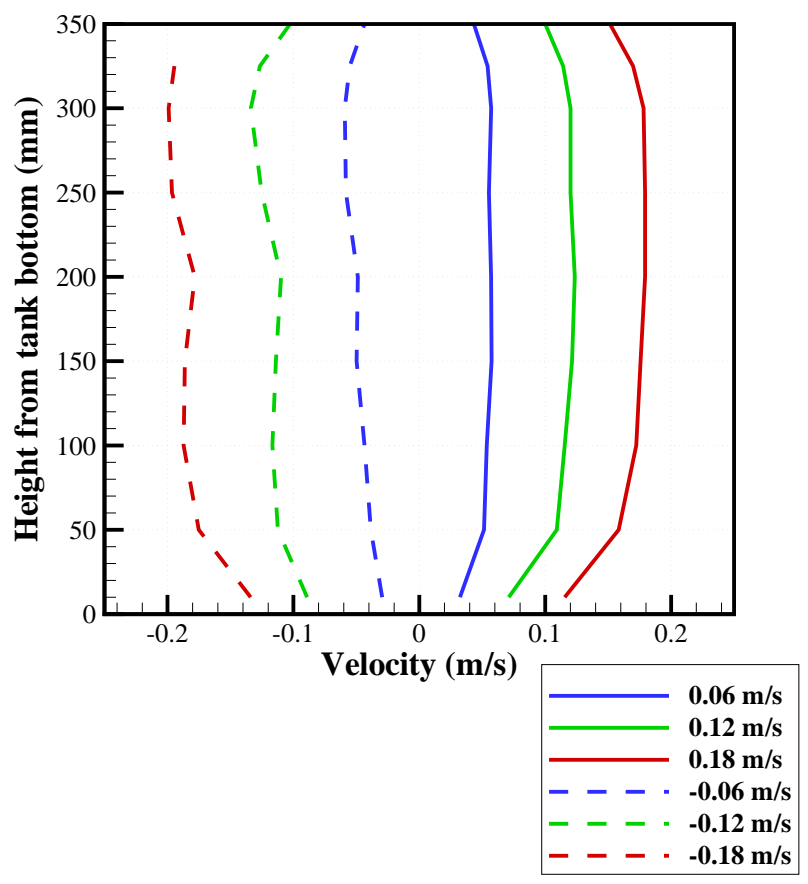

FIGURE 9. VERTICAL VELOCITY PROFILES MEASURED AT $5 \mathrm{~m}$ FROM THE WAVEMAKERS. THE REFERENCE VELOCITY CORRESPONDS TO THE MEASUREMENT AT A HEIGHT OF 200 mm FROM THE FLUME BOTTOM.

$0.6 \mathrm{~s}$ period, $110 \mathrm{~mm}$ for a $1.2 \mathrm{~s}$ period and $160 \mathrm{~mm}$ for a $1.8 \mathrm{~s}$ period). This is interesting from a technical perspective because it confirms that the system is well suited for the generation of large amplitude waves. For sake of comparison, it would require a stroke of $0.2 \mathrm{~m}$ for a piston wavemaker to generate a wave of $160 \mathrm{~mm}$ with $1.8 \mathrm{~s}$ period. Note that we were not able to generate greater waves than shown in Fig. 12 in the experiments (which would require an even greater stroke for a piston-type wavemaker) because we were limited by the height of the flume walls. They were not tall enough to avoid water spilling.

At this point, we must point out that, in our experiments, it was observed for finite depth and shallow water conditions that the wave quality is not sufficient for the new system to compete with conventional wavemakers. Indeed, the rate of generated harmonics is high in these conditions. However, it is well known that for finite depth conditions, the control of piston-type wavemakers requires corrections to be taken into account in order to achieve good quality of wave generation [7], [3]. Thus, the deficiencies of our system may be adressed also by including corrections in the control of the motors.

\section{Wave and current generation capability}

Wave and current can be generated by superimposing the control laws for wave generation and for current generation for the control of the rotational velocity of the motors. The result is a shifted harmonic function with average velocity governing the current intensity. Depending on the sign of the average velocity, waves propagating with or propagating against the current can be generated.

The graphs in the middle in Fig. 10 shows experimental results for a control with a $0.8 \mathrm{~s}$ period, an amplitude of variation of the rotational velocity of $400 \mathrm{rpm}$ and a positive rotational velocity average of $150 \mathrm{rpm}$. Like in previous cases, the same control is applied to both motors. In the experiments, the motors were set in rotation at average speed first an we waited until the current was established $(t<0$ in third graph of Fig. 10). Then, variations of the rotational velocity were applied. A ramp of duration 3 periods was applied when starting wave generation in order to allow a smooth transition between conditions with current only and conditions with current and waves. One can see that waves were generated in addition to the current. The wave height, in order of $40 \mathrm{~mm}$, appears to be smaller than in the case without current. Comparing the wave elevation signal with and without current, one can see that the first waves reach the wave gauge faster with the current. It is expected since the waves were following the current in this experiment. Also, one can see that, at the location were we measured current, the current goes faster with the waves (approximately $0.2 \mathrm{~m} / \mathrm{s}$ ) than without (approx. $0.1 \mathrm{~m} / \mathrm{s}$ ). The change in average velocity may be explained by wave and current interactions [8].

Last three graphs in Fig. 10 shows results for an experiment with period $0.8 \mathrm{~s}$, an amplitude of variation of the rotational velocity of $400 \mathrm{rpm}$ and a negative rotational velocity average of $150 \mathrm{rpm}$. The current is negative: it goes from the end of the flume towards the wavemaker. Without the waves, the current velocity is approximately $0.1 \mathrm{~m} / \mathrm{s}$. Like in the previous, superposing variations of the rotational velocity on the rotational velocity average allows waves to be generated. In comparison to the cases with waves propagating with current or without current, the wave height is significantly greater (approximately 70 $\mathrm{mm})$. Also, one can see that the waves reach the wave gauge significantly later because of the current that slows down energy propagation. The current velocity also increases with the waves going from approx. $-0.1 \mathrm{~m} / \mathrm{s}$ to $-0.2 \mathrm{~m} / \mathrm{s}$. Again, the change in average velocity may be explained by wave and current interactions [8].

\section{CONCLUSION}

In this study, we showed a numerical and experimental proof of concept for a new wave and current generation system in wave flumes. The system consists of axial-flow pumps controlled to generate an oscillatory flow through an orifice located in one of 

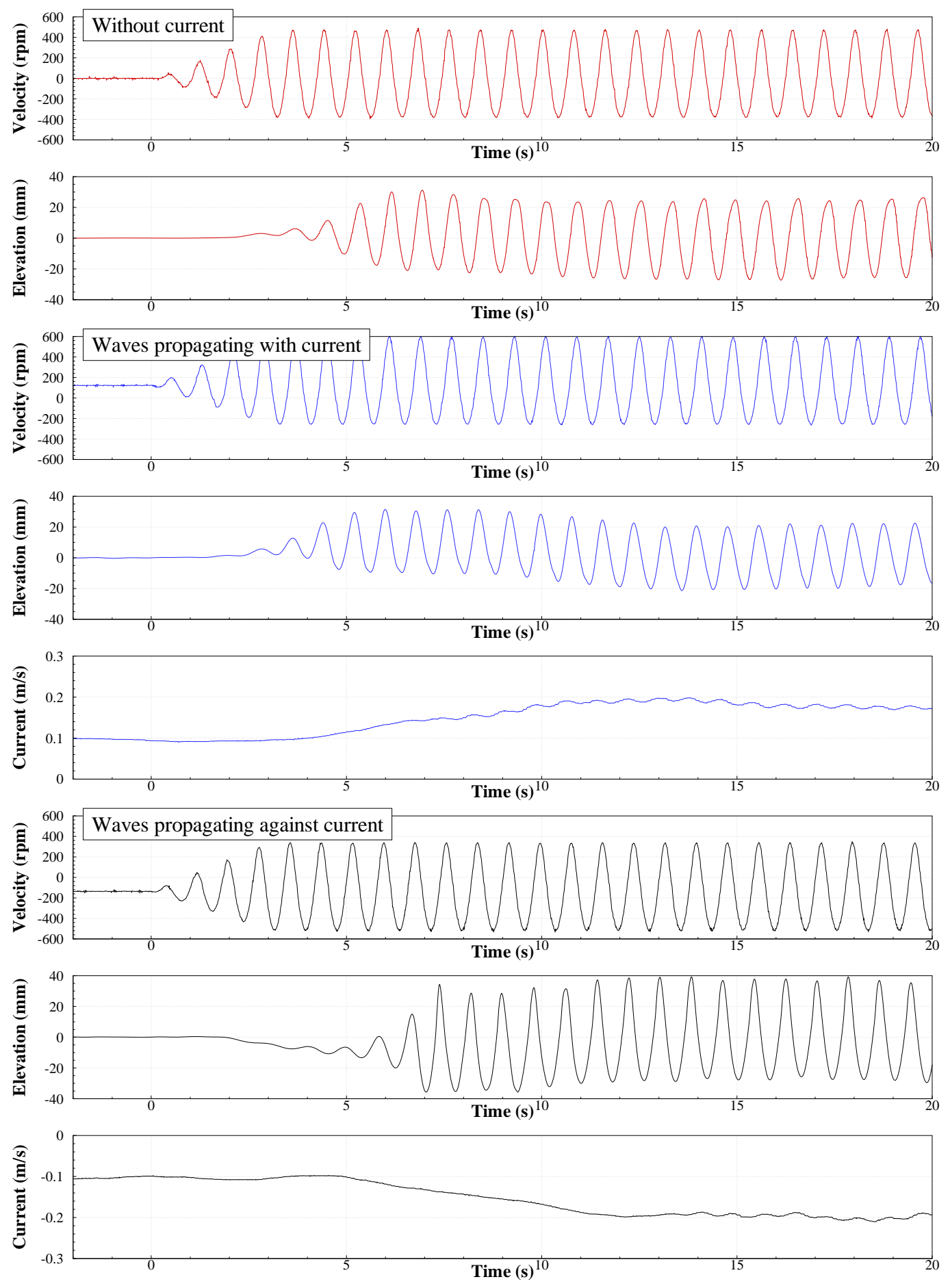

FIGURE 10. EXPERIMENTAL RESULTS FOR WAVE GENERATION, WAVES PROPAGATING WITH THE CURRENT AND WAVES PROPAGATING AGAINST THE CURRENT. TOP TWO GRAPHS ARE MEASUREMENTS OF MOTORS' ROTATIONAL VELOCITY AND WAVE ELEVATION AT A DISTANCE OF $2 \mathrm{~m}$ FROM THE WAVEMAKER. THE THREE NEXT GRAPHS ARE ROTATIONAL VELOCITY, WAVE ELEVATION AND CURRENT FOR A CASE OF WAVES PROPAGATING WITH THE CURRENT GENERATION. THE THREE LAST GRAPHS ARE FOR A CASE WITH WAVES PROPAGATING AGAINST THE CURRENT. IN ALL CASES, THE PERIOD IS $0.8 \mathrm{~s}$. 


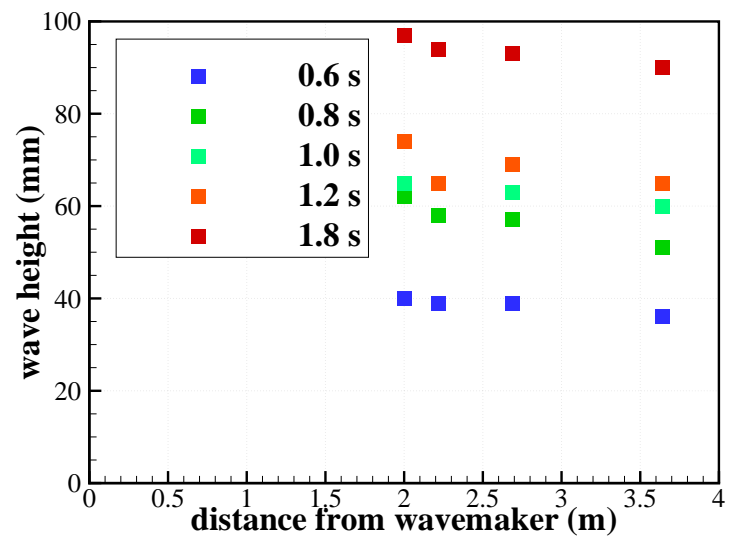

FIGURE 11. MEASURED WAVE HEIGHT AS A FUNCTION OF THE DISTANCE FROM THE WAVEMAKER FOR SEVERAL WAVE PERIODS. THE AMPLITUDE OF THE ROTATIONAL VELOCITY IS $400 \mathrm{rpm}$.

the wave flume wall. The oscillatory flow leads to generation of waves in the wave flume. If the flow average is different from zero, a current is superposed on the waves. In addition to easy generation of wave and current, the new wavemaking system has no end stops which allows easier generation of long and high waves in comparison to conventional wavemakers. Thus the new system may be particularly relevant for surf parks projects that are emerging all over the world.

An experimental set-up was designed and built at Ecole Centrale de Nantes. It was used to demonstrate that the new system can generate current, waves and waves propagating with or propagating against the current. However, during the experimental campaign, it appeared that the quality of the waves in finite water depth is poor in comparison to conventional technologies (piston-type wavemakers). The control of the new system must be improved in order to be competitive for wave and current generation in ocean engineering facilities.

\section{ACKNOWLEDGMENT}

Thanks go to CNRS, SATT Ouest Valorisation (TURBHO project) and Labex MER (ANR-10-LABX-19-01) for the financial support.

\section{REFERENCES}

[1] Dean, R., and Dalrymple, R., 1991. Water wave mechanics for engineers and scientists. World Scientific.

[2] Babarit, A., and Delvoye, S., 2015. Système de génération de vagues dans un bassin. Patent pending.

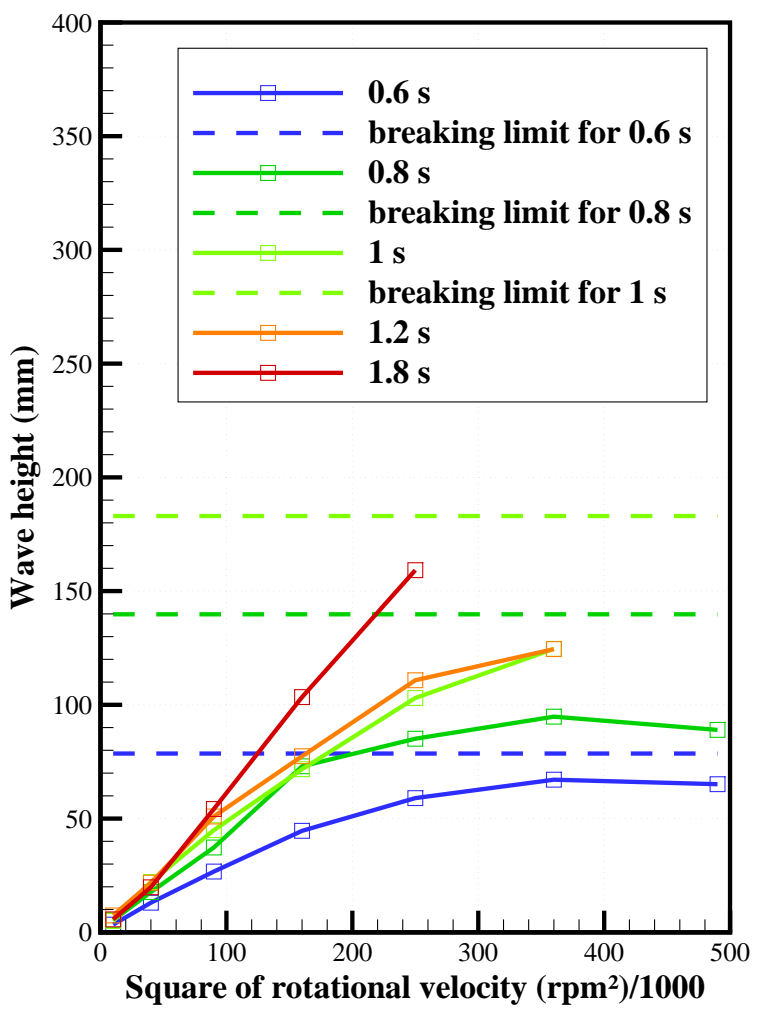

FIGURE 12. WAVE HEIGHT AS A FUNCTION OF THE SQUARE OF THE ROTATIONAL VELOCITY AMPLITUDE AND WAVE PERIOD. WAVE HEIGHT WAS EXTRAPOLATED FROM THE MEASUREMENTS FOR A WIDE FLUME.

[3] Zhang, H., and Schaffer, H., 2007. "Approximate stream function wavemaker theory for highly non-linear waves in wave flumes". Ocean engineering, 34(8-9), pp. 1290-1302.

[4] http: //www.wikiwaves/Wavemaker_theory, Last accessed on September, 29 ${ }^{t h}, 2016$.

[5] Queutey, P., and Visonneau, M., 2007. "An interface capturing method for free-surface hydrodynamic flows". Computers \& Fluids, pp. 1481-1510.

[6] Miles, J., 1967. "Surface-wave damping in closed basins". Proceedings of the Royal Society of London. Series A, Mathematical and Physical Sciences, 297(1451), pp. 459-475.

[7] Hudspeth, R., and Sulilsz, W., 1991. "Stokes drift in twodimensional wave flumes". Journal of Fluid Mechanics, 203, pp. 209-229.

[8] Teles, M.-J., Pires-Silva, A., and Benoit, M., 2013. "Numerical modelling of wave current interactions at a local scale". Ocean modelling, 68, pp. 72-87. 